Fecha de recepción: abril 2020

Fecha de aceptación: mayo 2020

Versión final: junio 2020

\section{Conexões com o mundo: verdade e representação na teoria política contemporânea}

Resumo: O objetivo geral deste ensaio consiste em investigar os elos existentes entre teorias do conhecimento e da política, ou, sendo mais específico, indicar os traços gerais de teorias políticas assentadas antes em representações, imagens e tropos do que em dogmas como os da realidade objetiva e das verdades autoevidentes da razão, que marcam o desenvolvimento da teoria e da prática política ocidental. Enquanto parcela considerável da reflexão sobre imagens e representações produzida no século XX focalizou aspectos relativos às artes, como atestam as obras de filósofos como Arthur Danto e Nelson Goodman, este artigo busca explorar as implicações latentes da "virada pictórica" estabelecida em diversas esferas da vida ao longo do século, sobre a teoria política contemporânea.

Palavras chave: Virada pictórica - Ceticismo - Relativismo.

[Resumos em espanhol e inglês nas páginas 168-169]

(1) Graduado em Ciências Sociais pela Universidade do Estado do Rio de Janeiro, mestre e doutor em Ciência Política pela Universidade Federal Fluminense. Possui experiência em docência nos níveis básico e superior, além de integrar, na condição de pesquisador, o Centro de Estudos sobre Desigualdade e Desenvolvimento, da UFRJ. Atualmente, realiza estágio pós-doutoral na UFRJ.

"Nada é tão traiçoeiro como o que é evidente". Joseph Schumpeter

O título deste ensaio remete à obra Connections to the World de Arthur Danto, cujo pano de fundo consiste na descrição da notável pluralidade de maneiras encontradas na história do pensamento para conferir sentido e inteligibilidade à experiência mundana, ou, em uma palavra, representá-la. O objetivo geral deste ensaio pode ser descrito como uma variação em torno de um tema implícito, mas pouco explorado ao longo das reflexões de Danto: investigar os elos existentes entre conhecimento e política no mundo contemporâneo, ou, sendo mais específico, indicar os traços gerais da teoria política contemporânea 
assentada, segundo a interpretação aqui esboçada, antes em representações, imagens e tropos do que em dogmas como os da realidade objetiva e das verdades racionais autoevidentes, que marcaram o desenvolvimento da teoria política clássica. Segundo Bourdieu, "toda teoria política contém, pelo menos no estado implícito, uma teoria da percepção do mundo social” (Bourdieu, 2003, p. 91), e é esse modo de conexão que será aqui explorado. A questão-chave que orienta este ensaio, portanto, é: que formas de interpretar o fenômeno político são desencadeadas pela "teoria da percepção do mundo social" pictorializada, característica do ocidente contemporâneo? O enfoque empregado aliará a consideração da experiência histórica e social à reflexão lógico-abstrata dos elos entre conhecimento e política, isto é, não se trata apenas de um exercício especulativo em torno da teoria política correspondente à cultura das imagens e representações que emergiu ao longo do século $\mathrm{XX}$, mas de identificar os modos de conceber a política que se desenvolveram em paralelo às intensas transformações produzidas nos modos de se conectar com a realidade nesse período.

\section{O paradigma da evidência}

A teoria politica constituiu-se historicamente, como campo de acesso pretensamente privilegiado à realidade. A tradição da teoria política proclamou, por diversas vias e em diversas ocasiões, formar um canal de contato com a verdade última por trás das aparências mundanas. Esse é um tema preferencial da filosofia política clássica, que remonta à distinção operada pelos gregos antigos entre physis e nomos, isto é, entre natureza e convenção. Barker (1978, p. 94) observa, a respeito desses marcadores conceituais: "a antítese da natureza e da Lei significava que o conteúdo moral da tradição, do costume e das instituições opunha-se ao código ideal de moralidade baseado na concepção de um princípio básico que regia a vida do homem". Cultivada principalmente pelos sofistas, essa antítese fornecia as bases para a crítica dos costumes tradicionais da polis, considerados contrários aos fundamentos naturais e permanentes da moralidade, pré-societários e pré-convencionais. Entre os sofistas, os prazeres individuais sobressaíam como o fundamento último da moralidade, mas esse fato não impediu a proliferação posterior de diferentes concepções sobre essa questão no bojo das teorias políticas clássica e moderna.

Popper (2008, p. 33) classificou as teorias calcadas na autoridade da realidade última das coisas como pertencentes ao paradigma do "otimismo epistemológico", a doutrina segundo a qual a verdade, embora oculta, pode revelar-se àquele que a persegue, seja pela intuição intelectual, seja pela percepção sensorial, isto é, seja por Descartes, seja por Bacon. Lessa (2010) a esse respeito, questionou qual seria o regime de validação da filosofia política ${ }^{1}$, isto é, qual seria o mecanismo epistemológico a partir do qual ela produziria e regularia a produção de verdades sobre seus objetos. Segundo Lessa, em contraste com a ciência, cujo regime de validação repousa nos mecanismos da prova e da demonstração, e da política prática, assentada nos processos de argumentação, a filosofia política toma como fundamento a evidência, compreendida como "uma convicção que se instala no sujeito, para a qual ele não tem o socorro da prova ou da demonstração” (Lessa, 2010, p. 232). 
Os casos em que essa forte convicção subjetiva se fez explícita são numerosos na história das ideias políticas. Lessa relembra a convicção de Rousseau a respeito da igualdade natural originária entre os seres humanos, conjectura que prescinde da razão e da história; evoca, também, as "verdades autoevidentes" dispostas por Thomas Jefferson no preâmbulo à Declaração de Independência dos Estados Unidos, direitos inalienáveis como a Vida, a Liberdade e a busca pela Felicidade.

A vinculação constante entre teoria política e evidência, porém, não deve ser confundida com alguma tendência natural e intrínseca da primeira ao terreno da imaginação e da inventividade. O mecanismo da evidência, em outras palavras, não porta como corolário necessário o ideal de progresso social e político, pois é possível a concepção naturalizada do mundo político tal como se apresenta, aceitando-se a ideia de que a conservação de sua regularidade e simplicidade sejam benéficas. Por que não seria desejável, então, a perpetuação da atividade política rotineira, tal como é? Por que a propriedade imaginativa no pensamento político deveria atuar como elemento de associação entre seus objetos e o plano da invenção?

Essas interrogações permitem-nos entrever uma das possibilidades (ou riscos) abertas à filosofia política: a afirmação filosófica do óbvio, da percepção ordinária, da versão de mundo do homem-na-rua, tal como Goodman a descreve:

For the man-in-the-street, most versions from science, art and perception depart in some ways from the familiar serviceable world he has jerry-built from fragments of scientific and artistic tradition and from his own struggle for survival. This world, indeed, is the one most often taken as real; for reality in a world, like realism in a picture, is largely a matter of habit (Goodman, 1978, p. 20).

Trata-se, aqui, do paradigma da evidência, porém em chave mais minimalista do que aquela representada pelas verdades ousadas (e mesmo revolucionárias) de Rousseau, Jefferson e tantos outros ${ }^{2}$. A evidência pode conduzir, assim, a uma forma de teoria politica do senso comum, isto é, a subordinação da filosofia à experiência comum do mundo. O paradigma da evidência assume, nesse caso, caráter notavelmente conservador. Destaca-se, nessa perspectiva, Strauss (1962), que aponta as propriedades epistemológicas superiores do common sense: trata-se do domínio da evidência irredutível, da certeza imediata, uma forma primária e fundamental de conhecimento que alicerça os conhecimentos de segunda ordem, como o científico e o filosófico. Ao senso comum são atribuídas qualidades metafísicas, uma metafísica espontânea, cujas verdades aí apreendidas não admitem dúvidas quanto ao seu conteúdo atual. Dessa perspectiva, soaria equívoco até mesmo falar-se em crenças ou convicções, pois o senso comum é o reduto da apreensão objetiva e categórica da realidade. A posição subordinada da ciência transparece: "If a logical positivist tries to give an account of a thing or a formula for a thing in terms of mere sense data and their composition, he is looking, and bids us to look, at the previously grasped thing" (Strauss, 1962, p. 315). 


\section{A virada pictórica}

A teoria política, tal como a descrevi até aqui se baseia em pressupostos específicos que lhe são anteriores, sobre a natureza e o alcance do conhecimento humano. O "regime de validação" da evidência, na expressão de Lessa (2010), de fato mostrou-se fundamental no bojo da tradição de teoria política, tal como a conhecemos desde os gregos - ainda que com notáveis variações. Da arché grega, o princípio unificador do mundo físico, ao senso comum de Strauss, mantém-se a ideia de um lastro a validar o conhecimento e, ipso facto, o conhecimento político.

É possível, contudo, identificar, ao longo da história, concepções alternativas sobre a natureza do conhecimento, que culminaram em uma cultura pública distinta e em uma teoria política sui generis. Popper (2008, p. 34) reconhece, em paralelo ao otimismo epistemológico, a existência de seu inverso, a visão pessimista, segundo a qual o conhecimento seguro é inalcançável. A racionalidade, nessa perspectiva, se apresenta como faculdade precária e limitada, enquanto a autoridade da tradição é considerada o guia mais apropriado para o gênero humano.

Poderíamos mencionar, ainda, uma espécie de otimismo mitigado, segundo o qual o conhecimento é possível, porém não nas bases do otimismo absoluto, que considera possível a apreensão de verdades indisputáveis. Segundo essa variação atenuada do otimismo, aos humanos é dado conhecer, seja pela razão, seja pela experiência, mas sempre cum grano salis, com reservas céticas, dada a falibilidade humana e dada, por consequência, a ausência de fontes de certeza absoluta para as opiniões e crenças. Nesse paradigma, que se alimenta em grande medida da influência da longeva tradição filosófica cética (Popkin, 2003), o conhecimento humano se ancora, basicamente em percepções, cuja validade repousa em outras percepções, e assim ao infinito, não sendo encontrado o lastro ou fundação capaz de garantir a infalibilidade das crenças, como sustentavam os otimistas.

No bojo desse otimismo mitigado, encontra-se uma teoria do conhecimento na qual as imagens e representações do pensamento assumem o protagonismo. Não que elas estivessem ausentes da perspectiva do otimismo asboluto, mas se encontravam, em maior ou menor grau, sob suspeita. Imagens e representações podem ser definidas como produtos do contato entre o sujeito e o mundo, ou, se quisermos, entre sujeito e experiência. Hume (2000) divide as percepções humanas em impressões - sensações, paixões, emoções, enfim, tudo que se produz no sujeito a partir de sua conexão com o mundo - e ideias. Quanto a estas últimas, Hume as define como "pálidas imagens dessas impressões no pensamento e no raciocínio [grifo nosso]" (Hume, 2000, p. 25) e completa: "Quando fecho os olhos e penso em meu quarto, as ideias que formo são representações exatas das impressões que antes senti [grifo nosso]" (Hume, 2000, p. 27).

O tema das imagens e representações mentais, que na filosofia de Hume passou ao proscênio, desempenhou papel secundário em diversos sistemas filosóficos otimistas desde a Antiguidade. Platão (1997), por exemplo, opôs, no célebre mito da linha dividida o Real, ou mundo inteligível, aos estados mentais dos indivíduos. Dentre esses últimos, o estado mais baixo do conhecimento é a eikasia, termo derivado de eikón (imagem), que corresponderia, em termos modernos, às faculdades da percepção e da imaginação. Um corolário dessa teoria do conhecimento, em que as imagens se contrapõem ao Real, consiste, 
segundo Danto (2005), no desprezo platônico pela arte mimética, pela imitação das coisas existentes, tal como se dá na pintura. Se as imagens participam de um modo inferior de conhecimento, mais inferiores ainda são as imagens de imagens - as imitações.

No âmbito da filosofia moderna, Descartes (2005) concebe a imaginação como domínio de figurações subjetivas dirigidas pelo entendimento, pelo componente racional da alma, ainda que nem sempre em estado de vigília, pois, como afirma Descartes, "as coisas que nos são representadas no sono são como quadros e pinturas” (Descartes, 2005, p. 33). Sem o concurso do entendimento, é possível imaginar que haveria apenas uma sucessão atomizada, fragmentária e ininteligível de imagens. A ideia de um objeto material não poderia estar confinada aos limites estreitos da imaginação, uma vez que as infinitas mudanças a que estão expostos são concebíveis (pelo entendimento), mas não representáveis (pela imaginação). O exemplo do quiliógono é esclarecedor a esse respeito: trata-se de uma figura geométrica de mil lados, que, embora seja concebida pelo entendimento, não é plenamente representável -como imagem mental-por demandar um grau de atenção e esforço figurativo além das possibilidades da imaginação. Segundo Kiraly (2012), para Descartes "Os pensamentos sem imagem são verdadeiros de um modo ao qual o pensamento com imagem não pode se igualar" (Kiraly, 2012, p. 92), e acrescenta: "A imagem está relacionada ao corpo, o que não a permite ser um duplo confiável do pensamento" (Kiraly, 2012, p. 92).

É principalmente com Montaigne, no século XVI, Hume, no XVIII, e a redescoberta moderna do ceticismo narrada por Popkin (2003) que as imagens de pensamento alcançam um estatuto epistemológico que em raras oportunidades lhe fora conferido na tradição filosófica. Como assinala Kiraly (2012, p. 55): “O ceticismo é a única disposição filosófica que suporta a aparência pela aparência, a representação pela representação, não assume que possa existir conhecimento último do mundo".

Foram vários os desenvolvimentos teóricos posteriores, no curso dos séculos XIX e XX, que reforçaram e suplementaram a (re)valorização das imagens e representações como veículo de conhecimento legítimo, na forma de uma miríade de filosofias antidogmáticas. Pragmatismo, pós-estruturalismo, relativismo epistemológico, foram alguns dos paradigmas fertilizados pelo ceticismo, seu otimismo mitigado quanto ao conhecimento e sua orientação pictorialista. Deleuze (2006), ao criticar o modelo de representação que associa conhecer a reconhecer, isto é, a contemplar passivamente o mundo objetivo, busca afirmar a potência criadora das imagens do pensamento frente ao dogma das essências, de extração platônica. Danto (2005), por sua vez, ao comentar as relações entre estilo e homem, afirma: "somos sistemas de representações, maneiras de ver o mundo, representações encarnadas" (Danto, 2005, p. 292) e acrescenta: "pouco importando se são sistemas de palavras ou de imagens ou ainda de ambas, o que é mais provável” (Danto, 2005, p. 293). Mas talvez seja Nelson Goodman o filósofo contemporâneo que se dedicou com mais ênfase e rigor a sustentar a centralidade das imagens e representações para fixar verdades relativas e parciais, as únicas verdades possíveis, no registro antidogmático aqui descrito. Assim, observa Goodman (1978, p. 3): "We are confined to ways of describing whatever is described (...) Such of these versions as are depictions rather than descriptions have no truthvalue". O tema da verdade, tão caro às teorias otimistas, se afigura, para Goodman, como categoria não aplicável, ao menos na acepção dogmática, essencialista, que a caracterizara. 
A verdade é produzida, afirma Goodman, pela justaposição ou contato entre visões, imagens de mundo distintas, e são portadoras de validade circunstancial, atinente a cada uma dessas imagens; ademais, em muitos casos, outras propriedades são mais relevantes que a verdade. Uma sonata, por exemplo, não poderia ser considerada verdadeira ou falsa, mas pode ser considerada mal ou bem executada, mais ou menos pungente.

Esse processo, ocorrido no âmbito das teorias do conhecimento, que podemos intitular, seguindo Mitchell (1994), "virada pictórica", manifestou-se paralelamente em muitos outros campos da atividade humana. Dentre os principais experimentos realizados no contexto das vanguardas artísticas contemporâneas -suprematismo, surrealismo, dadaísmo, etc- a quase totalidade comungou da fuga à representação tradicional, isto é, à referencialidade que constituía uma espécie de atributo nuclear do classicismo. A arte contemporânea desincumbiu-se, em grande parte, da mimese, da imitação da realidade, do compromisso de fidelidade aos referenciais objetivos, a tal ponto que Clement Greenberg, em notável exercício crítico, observou: "Content is to be dissolved so completely into form that the work of art or literature cannot be reduced on whole or in part to anything not itself" (Greenberg, 1961, p. 8). Picasso, Mondrian, Miró, Kandinsky, todos em algum momento abandonaram a tarefa, agora considerada naive, de retratar o individuo, a natureza, o mundo, e se dedicaram às experimentações formais, deslocando-se, assim, da extensão para a expressão.

Na poesia, as referências mais óbvias da virada pictórica são as obras de vanguarda, como Mallarmé, Marinetti, Pound, os concretistas, em suma, aqueles cuja atenção se dirigiu aos aspectos visuais, imagéticos, do poema, no poema como artefato do e sobre o mundo. Destaca-se, nessa visada, o poema "Certeza", de Octavio Paz: Si es real la luz blanca/de esta lámpara, real/la mano que escribe, ¿son reales/los ojos que miran lo escrito?/De una palabra a la outra/lo que digo se desvanece./Yo sé que estoy vivo/entre dos parêntesis" (Paz, 1987, p. 66).

\section{Conclusão: Política e experimentação formal}

Se o processo que descrevi acima se irradiou em tantas direções, seria de se esperar que alcançasse também a teoria política contemporânea e decantasse em instituições, práticas e processos políticos concretos. Impõe-se, portanto, a questão: como se exprimiu, na teoria política, o conjunto de valores, crenças e atitudes emergentes a partir da virada pictórica? Uma possível resposta pode ser encontrada nos ventos relativistas que se fizeram sentir nesse domínio. A virada pictórica na política se traduziu em um enquadramento metateórico, no qual cada imagem do mundo político, cada sistema fechado de teoria política deve abrir-se ao contato com a experiência. São, na imagem devida a Edmund Burke, como que "raios de luz atravessando um meio denso [...] desviados, pelas leis da natureza, de sua linha reta" (Burke, 1982, p. 90). Isto corresponde à admissão da verdade autoevidente, do estado de natureza, dos direitos naturais, do senso comum e tantos outros conceitos caros à teoria política como idéias orientadoras, horizontes regulatórios e não como elementos de uma realidade apriorística. Em outros termos, pode-se afirmar que esses conceitos fazem 
parte do mundo, mas também se referem a ele, possuindo, portanto, um pé na realidade e outro fora dela.

A teoria política típica de um espaço público pictorializado apresenta, assim, a feição de uma metateoria, um framework no qual as muitas imagens e versões de mundo coalescem e colidem, e a nenhuma dessas versões é conferida a palavra final. Observa-se, aqui, o reconhecimento e a afirmação da diaphonia, a "discrepância insolúvel" (Lessa, 1997, p. 209) entre essas imagens. Convém notar que disso não resulta um estado de coisas necessariamente marcado pela indecisão absoluta, o relativismo radical ou alguma espécie de anomia teórica que, à primeira vista, poderia ser inferida desses princípios. A teoria politica pictorializada, a bem dizer, não abre mão da fixação de verdades no espaço público, mas rompe com o que Lessa (1997, p. 215) denomina idiotia das teorias dogmáticas, que postulam alcançar a verdade de maneira privada, pela via da intuição ou da evidência subjetiva. A verdade política repousa, agora, em acordos, assentimentos comunais e passam a ser reguladas por rituais e procedimentos públicos de agregação.

A investidura dessa reserva cética sobre as pretensas verdades últimas relativas à esfera pública remonta ao século XIX, às críticas de Stuart Mill à imposição da opinião comum às minorias desviantes, $\mathrm{e}$ aos questionamentos de Jeremy Bentham àquilo que considerava dogmas políticos, como a Declaração Universal dos Direitos do Homem e do Cidadão. No início do século XX, Schumpeter (1961) rearticula essas críticas, ao analisar a doutrina democrática que denomina "clássica", associada, particularmente à filosofia política de JeanJacques Rousseau. Esta se caracteriza, segundo Schumpeter, por enfatizar as categorias da vontade geral e do bem comum, de tal forma que os métodos decisórios são concebidos como meios de se satisfazer a primeira e alcançar o segundo. A presença de procedimentos formais democráticos, como eleições livres, periódicas e baseadas em sufrágio universal, por exemplo, não preenche os requisitos necessários para a existência de uma democracia, nesse paradigma; é preciso, sobretudo, que os representantes eleitos cumpram a função para a qual foram designados: satisfazer a vontade geral e decidir sempre de acordo com o bem comum.

Schumpeter submete a doutrina clássica e seus dois pilares conceituais a um escrutínio em termos empíricos, tratando-as como hipóteses sujeitas ao tribunal da experiência: "essas presunções [democráticas] correspondem a simples declarações de fato, cada um dos quais terá de ser provado" (Schumpeter, 1961, p. 301). Frente à ideia de um bem comum unívoco, o autor opõe a diversidade de concepções relativas de "bem" existentes, ignoradas pela teoria rousseaniana, ou interpretadas por ela como oriundas da ignorância, da desinformação ou da incivilidade, hipóteses facilmente contestáveis em termos factuais. Uma vez que o bem comum é o vértice para o qual converge a vontade geral, a impugnação da primeira alcança a segunda; não obstante, Schumpeter analisa a possibilidade de que o processo político corresponda, de alguma maneira a uma suposta vontade geral capaz de comandá-lo; não uma vontade de todos, mas ampla o suficiente para compor uma maioria eleitoral. Se esse fosse o caso, a democracia bem poderia ser definida como o governo da vontade da maioria, e de certa forma, de governo da vontade popular.

A objeção a essa hipótese leva em consideração as dificuldades operacionais que qualquer governo teria para computar e dar seguimento à vontade popular referente aos diversos assuntos com os quais há de lidar, o que demandaria uma rede de comunicação e processa- 
mento de informações incalculável. Mas o âmago da refutação de Schumpeter é ainda outro: refere-se à incapacidade de os próprios indivíduos formarem vontades definidas, claras, ausentes de ambiguidade e fundamentadas a respeito dos inúmeros problemas com que se defrontam em sua experiência social, algo além do equipamento cognitivo humano, tal como o conhecemos. A diaphonia, com Schumpeter, é interiorizada: há uma discrepância insolúvel dentro dos sujeitos, imagens instáveis e ambivalentes, representações fluídas sobre a vida social que tornam inviável a apreensão de qualquer vontade geral fixa e unitária. Na trilha estabelecida por Mill, Bentham, Schumpeter e outros teóricos liberais, o século XX assistiu a uma notável retração da teoria política, ao relativo abandono das tentativas de se alcançar teorias substantivas sobre como deve se estruturar a esfera política ${ }^{3}$. Boa parte das imagens de mundo produzidas na teoria política contemporânea afastou-se da concepção de utopias e marchou à figuração de desenhos institucionais, isto é, ao desenho de regras e rituais capazes de regular a diaphonia, de garantir acordos e coalizões entre as muitas verdades habitantes do espaço público, como é o caso das teorias democráticoprocedimentais de Dahl (1956), Kelsen (1955), Habermas (1994) e de todo um eixo de teorias da democracia calcadas na centralidade da deliberação como fonte de sua legitimidade (Dryzek, 1990). Um paralelo aqui pode ser traçado entre o experimentalismo formal das vanguardas artísticas a que fiz referência na seção anterior e o experimentalismo formal das normas e procedimentos políticos que se alastrou pela teoria política no século XX. Se para um clássico como Aristóteles, a forma de governo se mostrava menos importante que o modo concreto de se exercer o poder, visando ou não ao bem comum, $o$ vanguardismo democrático-liberal do século XX ocupou-se mais com as formas enquanto veículo de expressão livre e desimpedida de crenças políticas do que como tradução direta e evidente do bem, da verdade, da justiça e tantas outras categorias tradicionais do léxico político clássico.

Um último aspecto que gostaria de ressaltar da política pictorializada é o requisito de perspectivismo que ela encerra. Ora, se o esforço teórico contemporâneo direcionou-se às regras e rituais capazes de garantir graus mínimos de convivência e intercâmbio harmoniosos entre as muitas crenças, podemos concluir que essa condição só pode ser preenchida se há, por parte dos atores políticos, a capacidade de colocar-se, imaginariamente, na perspectiva do Outro. Essa aptidão constitui, por assim dizer, a pedra de toque da tolerância política. $\mathrm{O}$ valor da tolerância, portanto, aparece como outro aspecto fundamental da política pictorializada, e deita raízes em um passado razoavelmente remoto. A história da tolerância política é longa e ultrapassa as fronteiras da política institucional propriamente dita. Se, como observou Lessa (2004, p. 11) "Quadros e pinturas, por vezes, possuem a força filosófica de proposições" esse aspecto pode ser melhor compreendido através do engenho de Diego Velázquez. Em seu quadro As Meninas, o pintor produziu um artifício interpretativo que antecipou em alguns séculos as proposições contemporâneas sobre a relevância do perspectivismo para o conhecimento e a moralidade. Velázquez, na obra, busca retratar não apenas pessoas e coisas, mas uma perspectiva, um modo de vê-las que não o seu. Esse exercício é revelado (I) pela aparição do próprio Velázquez na cena, ao fundo e (II) pela introdução dos reflexos, em um espelho, das figuras do rei e rainha de Espanha, Felipe IV e Mariana de Áustria, como que a contemplar toda a cena, de um ponto exterior ao enquadramento. 
Os reflexos no espelho sugerem ser estes, rei e rainha, os verdadeiros observadores da situação, não o próprio pintor; sugestão reforçada pelo conjunto da cena: o que se vê são elementos constituintes da forma de vida dos reis, o que se retrata é sua corte, e os olhares reverentes dos cortesãos ao casal real são perceptíveis. Velázquez parece expor uma experiência que imagina não ser a sua própria, de súdito. Pelo uso da imaginação, põe-se a encarnar os soberanos, e assim o fazendo, segue fortuitamente o ensinamento de Maquiavel, que cerca de um século antes, afirmara: "para conhecer bem a natureza dos povos, é preciso ser príncipe e para conhecer bem a dos príncipes, é preciso ser povo” (Maquiavel, 2001, p. 12).

\section{Notas}

1. Empregamos, aqui, os termos teoria e filosofia política como intercambiáveis. Seu sentido, neste texto, se aproxima ao estabelecido por Sabine (apud Gunnell, 1979:19): "a collection of writings (...) product of hilosophical writers and their disciplined investigation of political problems".

2. Um exemplo temporalmente próximo a Rousseau e Jefferson é dos revolucionários franceses e sua Verité.

3. O que não significa a inexistência de teorias à moda clássica, vinculadas ao paradigma da evidência, como as de Robert Nozick e John Rawls, por exemplo.

\section{Referências Bibliográficas}

Barker, E. (1978). Teoria Política Grega. Brasília: EdUnB.

Bourdieu, P. (2003). Questões de Sociologia. Lisboa: Fim de Século.

Burke, E. (1982). Reflexões sobre a Revolução em França. Brasília:UnB.

Greenberg, C. (1961). “Avant-garde and Kitsch” In: Greenberg, C. Art and Culture, Boston: Beacon Press.

Hume, D, (2000). Tratado da Natureza Humana. São Paulo: Unesp.

Dahl, R. (1956). A Preface to Democratic Theory. Chicago: University of Chicago Press.

Danto, A. (2005). A Transfiguração do Lugar-Comum. São Paulo: Cosac Naify.

Danto, A. (1997). Connections to the World. Berkeley: University of California Press.

Deleuze, G. (2006). Diferença e Repetição. Rio de Janeiro: Graal.

Descartes, R. (2005). Meditações Metafísicas. São Paulo: Martins Fontes.

Dryzek, J. (1990). Discursive Democracy: Politics, Policy and Political Science. New York: Cambridge University Press.

Goodman, N. (1978). Ways of Worldmaking. Indianapolis: Hackett.

Gunnell, J. (1979). Political Theory: Tradition and Interpretation. Cambridge: Winthrop Publishers. 
Habermas, J. (1994). “Three normative models of democracy” In: Constellations, V. 1, No $1,1-10$.

Kelsen, H. (1955). "Foundations of Democracy” In: Ethics, V.66, No 1, 1-101.

Kiraly, C. (2012). Ceticismo e Política. São Paulo: Giz Editorial.

Lessa, R. (2004). "A Condição Hum(e)ana e seus Ensaios" In: Hume, D. Ensaios Morais, Políticos \& Literários. Rio de Janeiro: Topbooks.

Lessa, R. (2010). “Da Filosofia Política e da Crença ou das condições necessárias para a experiência do pensamento sobre a política" In Novaes, A. (Org.) Mutações: A experiência do pensamento. São Paulo: SESC.

Maquiavel, N. (2001). O Príncipe. Bauru: Edipro.

Mitchell, W.J.T. (1994). Picture Theory: Essays on Verbal and Visual Representation. Chicago: The University of Chicago Press.

Paz, O. (1987). The Collected Poems of Octavio Paz 1957-1987. New York: New Directions Book.

Platão (1997). A República. São Paulo: Nova Cultural.

Popkin, R. (2003). The History of Scepticism From Savonarola to Bayle. New York: Oxford University Press.

Popper, K. (2008). Conjecturas e Refutações. Brasília: EdUnB.

Schumpeter, J. (1961). Capitalismo, Socialismo e Democracia. Rio de Janeiro: Fundo de Cultura.

Strauss, L. (1962). An Epilogue In: Storing, H . Essays on the Scientific Study of Politics. New York: Holt, Rinehart and Winston.

Resumen: El objetivo general de este ensayo es investigar los vínculos entre las teorías del conocimiento y la política, o, más específicamente, indicar las características generales de las teorías políticas basadas en representaciones, imágenes y tropos en lugar de dogmas como los de la realidad objetiva, verdades evidentes de la razón, que marcan el desarrollo de la teoría y práctica política occidental. Si bien una parte considerable de la reflexión sobre imágenes y representaciones producidas en el siglo XX se ha centrado en aspectos relacionados con las artes, como atestiguan las obras de filósofos como Arthur Danto y Nelson Goodman, este artículo busca explorar las implicaciones latentes del "giro pictórico" establecido en diversas esferas de la vida. a lo largo del siglo en la teoría política contemporánea.

Palabras clave: Giro pictórico - Escepticismo - Relativismo.

Abstract: The general goal of this essay is to investigate the links between theories of knowledge and politics, or, more specifically, to indicate the general features of political theories based on representations, images and tropes rather than on dogmas such as those of objective reality and self-evident truths of reason, which mark the development of Western political theory and practice. While a considerable portion of the reflection on 
images and representations produced in the twentieth century has focused on aspects related to the arts, as attested by the works of philosophers such as Arthur Danto and Nelson Goodman, this article seeks to explore the latent implications of the "pictorial turn" established in various spheres of life throughout the century on contemporary political theory.

Keywords: Pictorial turn - Skepticism - Relativism.

[Las traducciones de los abstracts fueron supervisadas por el autor de cada artículo] 